\title{
Emotions in Twitter communication and stock prices of firms: the impact of Covid-19 pandemic
}

\author{
Suparna Dhar · Indranil Bose
}

Accepted: 10 November 2020/Published online: 28 January 2021

(C) Indian Institute of Management Calcutta 2021

\begin{abstract}
In this paper, we explored two key aspects of organization theory-organizational communication in the face of crisis and the influence of emotions expressed in social media communication and their impact on stock prices of firms. We extracted emotional content from 189,303 tweets and collected financial data for six quarters for 105 companies listed on the New York Stock Exchange from the Fortune 1000 list of companies. We operationalized a set of metrics to measure emotion in organizational tweets. Our analysis showed that the operationalized metrics to measure emotion expressed in organizational tweets were significant predictors of stock prices of firms. Further analysis showed a moderation effect of the crisis on the association between emotion expressed in organizational tweets and stock prices in the presence of control variables. The study provides a detailed analysis of constituent positive (happiness) and negative (anger, fear, and sadness) emotions in organizational tweets and their association with stock prices of firms. Practitioners and regulators may use the analysis and the metrics to assess organizational
\end{abstract}

S. Dhar $(\bowtie)$

NSHM Knowledge Campus, 124 BL Saha Road,

Kolkata 700053, India

e-mail: suparnadhar@gmail.com

I. Bose

Indian Institute of Management Calcutta, Kolkata,

West Bengal 700104, India

e-mail: bose@iimcal.ac.in communication and better leverage Twitter for crisis response. This paper showcases organizational crisis response of Twitter and its financial impact.

Keywords Crisis management - Emotion analysis · Financial impact - Organizational performance - Text mining $\cdot$ Twitter

\section{Introduction}

Online social networking has permeated the domain of business management, introducing unique unprecedented aspects of business information management (Luo et al. 2013). It has become the mainstay of organizational communication, interaction, and information exchange with external stakeholders (Dhar 2019). It allows people to create and exchange content and publicly voice and support ideas, concerns, opinions, and views. Organizational online social networking spans passive and active, proactive and reactive, and tactical and strategic uses (Sinclaire and Vogus 2011). Organizations engage with end consumers on online social networks for product cocreation, consumer feedback, consumer insights, and market intelligence. In short, organizations employ online social networking for a variety of operational and strategic purposes. 
The COVID-19 crisis that started towards the end of 2019 shocked the entire humanity. It grew by leaps and bounds in early 2020. Thousands of people across the world got affected by the disease every day. In March 2020, the World Health Organization (WHO) declared COVID-19 as a pandemic (WHO 2020). Within days many countries across the world declared partial or full lockdown (WEFORUM 2020). The lockdown had immediate and far-reaching effect on businesses (McKinsey 2020). Many organizations had to stop operations or make alternate arrangements, such as work from home. The crisis proved to be a double-edged sword, with concerns for stakeholder health on one hand and managing business losses on the other. The uniqueness and the magnitude of the COVID-19 crisis generated academic interest from the perspective of organizational crisis management. A crisis generates uncertainty, that is marked with human emotions, such as anger, fear, sadness (Jin et al. 2010). During a crisis, these emotions get reflected in Twitter communication (Do et al. 2016). In this paper, we explore emotions expressed in organizational tweets before and during the COVID-19 crisis.

Research Question 1: What were the emotions expressed in organizational tweets before and during the COVID-19 crisis?

Past researchers have studied the organizational use of online social networking for brand promotion, marketing, human resource management, knowledge and learning management, innovation functions (Dhar 2019). Extant literature has shown an association between emotions expressed in organizational communication and financial performance (Fleming et al. 2005). Researchers have found that social media usage metrics have a causal relationship with stock performance (Luo et al.2013). In this paper, we study the association between emotions expressed in organizational tweets and the organization's stock price performance. There is academic interest in the study of the impact of uncertainty and crisis on organizational performance (Grove et al. 2011; Nakashima and Ota 2016). We extend our analysis to investigate the impact of the COVID-19 crisis on the association between emotions in organizational tweets and stock price performance for firms.
Research Question 2: How do the emotions expressed in organizational tweets influence stock prices of firms?

Research Question 3: Does a crisis affect the association between emotions expressed in organizational tweets and stock prices of firms?

This paper presents related work and background in "Related works and background" section and elaborates on the research method in "Research method" section. The analysis and results are presented in "Analysis and results" section. The exploratory analysis of emotions in organizational tweets before and during the crisis is presented in "Comparing Twitter emotions before and during crisis" section, an analysis of Twitter usage on stock price performance is described in "Influence of volume of Tweets on stock price" Section, and the effect of the crisis on the association between emotions expressed in organizational tweets and stock prices of firms is detailed in "Influence of emotions in Tweets on stock price" section. The discussion of the research findings is provided in "Discussion" section, and the concluding remarks in "Conclusion" section.

\section{Related works and background}

Social networking and organizational performance

Organizations use social networking sites for stakeholder engagement and communication (Wang and Yang 2020). Strategic uses of social networking and stakeholder communication in online environments offer business value (Culnan et al. 2010). Digital communication media, such as Twitter, have transformed public communication and managed public perception, specifically in a crisis (Chew and Eysenbach 2010). Organizations leverage the power of online social networks to generate value, and tangible and intangible capital, in a globalized virtual work environment (Dhar 2019). Firms communicate and share information with stakeholders and the general public on social networking platforms. Scholars have found that the social media metrics related to the size of the network, the traffic generated, the frequency of usage generate brand value, customer engagement, and improved financial performance (Yoon et al. 2018).

Scholars have found that online comments about organizations influence their financial performance 
(Yoon et al. 2018). Past studies have investigated the influence and predictive ability of social media metrics, such as usage metrics (volume of posts), traffic (page views), network (followers, friends, reach), type of content (text and multimedia), response to content (like, share, impressions), and content quality (sentiments, emotions), on organizational performance (Osatuyi and Yoosefi 2019; Signorini et al. 2011; Yoon et al. 2018). Extant studies have found that online comments influence organizational revenue (Yoon et al. 2018). Scholars have applied the efficient market hypothesis (Fama 1970) to study the impact of usage of organizational social media on stock price of firms (Luo et al. 2013). Mao et al. (2012) have found a positive association between tweet volume and stock price. Osatuyi and Yoosefi (2019) have reported that higher volume of tweets have a negative influence on stock price.

\subsection{Human emotions}

Emotions affect human behavior. In an organizational context, emotions affect managerial behavior and decision making (Wisittigars and Siengthai 2019). Scholars have found that managing emotions, popularly known as emotional intelligence, is associated with job performance and leadership qualities (Goleman 1998). The affective experiences and emotions influence managerial decisions and consequently organizational performance (Fenton-O'Creevy et al. 2011; Seo and Barrett 2007). In the first part of this paper, we study the association between emotions expressed in organizational tweets and the organization's financial performance.

The psychoevolutionary theory has categorized anger, fear, joy, sadness, disgust, surprise, trust, and anticipation as the eight basic emotions (Plutchik 1980). These basic emotions include three positive (anticipation, joy, and trust) and four negative (anger, fear, disgust, and sadness) emotions (Fredrickson et al. 2003). The basic emotion, surprise, does not belong to either the positive or the negative set of emotions (Fredrickson et al. 2003). Ortony and Turner's (1990) study on emotions from the psychological perspective have reported that most typologies of basic emotions have identified anger, fear, happiness, and sadness among the basic emotions. Scholars in the fields of Psychology and Computing have focused on these four emotions in their research (Dinev et al. 2015; Yin et al. 2014). Consequently, we identify anger, fear, happiness, and sadness as the emotions of interest for our study.

\subsection{Crisis communication}

There is academic interest in understanding the impact of uncertainty and crisis on organizational performance (Grove et al. 2011; Nakashima and Ota 2016). A crisis is defined as "low-probability, unanticipated, high impact (i.e., harmful) events that are unpredictable, surprising, and threaten the viability of the organization" (Williams et al. 2017, p. 737). Businesses face a wide range of crisis events-accidents, acts of terrorism, information and data security violations, natural catastrophes, product recalls, social media rumors, and more (Boin 2009). Typically, a crisis comes in an unexpected manner. It offers limited time to respond and affects the core values of the organization. Organizations need a better understanding of crises to develop their crisis management strategy and build resilience against crises.

Crises events offer organizations an opportunity to communicate with stakeholders (Simpson et al. 2013). The crises provide organizational stakeholders with an opportunity to demonstrate leadership. The leaders mitigate the risk of chaos and confusion and harness the available information to identify opportunities to enhance performance and avoid fomenting trouble (Williams et al. 2017). The crisis management teams often play a critical role in organizing resources to contain stress, minimize the adverse impact of crisis, and pave the way for faster recovery (Barton et al. 2015). Finally, the leaders, the crisis management team, and the stakeholders need to synchronize their efforts and actions in managing the crisis. The organizational communication and stakeholder interaction on online social networking platforms often reflect this enhanced communication.

Scholars have studied human emotions as a consequence of environmental stimulus. The integrated crisis mapping model (ICM), proposed by Jin, Pang, and Cameron (2007), has mapped negative emotions to a crisis (Jin et al. 2007). The situational crisis communication theory proposed by Coombs (2007) has posited that informing and adjusting information can diminish the adverse impact of the crisis on organizational reputation when the organization does not have direct responsibility for the crisis. The 
leadership team need to demonstrate high emotional intelligence and manage their emotions in these stressful situations (Mackinnon et al. 2013). Studies have shown that emotional cues are transmitted in communication on a digital medium (Kato et al. 2007). In a crisis, organizations need to manage their emotions and the emotions expressed in their communication with stakeholders to overcome the adversities presented by the crisis (Wisittigars and Siengthai 2019).

\section{Need for the study}

Crises are characterized by negative emotions such as fear, anxiety, worry which lead to negative sentiments (Mandel et al. 2012). A crisis is marked by an increase in the number of tweets expressing negative public sentiment (Chew and Eysenbach 2010). Organizational reputation and image and external stakeholders are usually negatively affected during a crisis (Laporte and Consolini 1991). Effective communication with stakeholders may avert the negative impact of crisis on the organization. Emotions evoked through organizational communication in a crisis are relevant to the achievement of organizational goals (Jin et al. 2010). Emotional cues in organizational communication during a crisis affect stakeholder behavior ( $\mathrm{Lu}$ and Huang 2018).

Past research has found a causal relationship between organizational use of social networking sites and financial performance (Luo et al. 2018,2013; Yu et al. 2013). Organizations use Twitter as a major digital channel for communication (Chew and Eysenbach 2010; Mandel et al. 2012). Scholars have studied the causal relationship between Twitter usage metrics and organizational performance (Culnan et al. 2010; De Choudhury and Counts 2012). Zhou et al. (2016) have studied the association between emotions in social media and stock price. The paper stressed the need for a detailed study of the connection between emotions and stock price. A subsequent study of the effect of organizational tweets on firms' stock price performance have showed a significant positive impact of positive emotions, but no significant impact of negative emotions (Osatuyi and Yoosefi 2019).

Chew and Eysenbach (2010) have studied the efficacy of using content analysis of Twitter data to measure public perception during the pandemic. Signorini et al. (2011) have used Twitter data to study public sentiment and track disease activity during the breakout of H1N1 flu. Mandel et al. (2012) have used Twitter data to do a demographic analysis of sentiments during the Irene hurricane disaster. The COVID-19 crisis has led researchers to study various aspects of the COVID-19 crisis (Barkur et al. 2020; Pastor 2020). Barkur et al. (2020) have used Twitter data to study public sentiment during the COVID-19 crisis.

In order to address the research questions specified earlier our paper has explored the effect of the COVID-19 crisis on the relationship between emotions expressed in Twitter data and stock price performance of first. We contribute to the growing literature on organizational use of Twitter in a crisis, and its consequences on organizational performance.

\section{Research method}

We collected data from January 1, 2019, to June 30, 2020, for the exploratory study. To explore the emotions in Twitter data and its association with organizational performance, we selected the top 150 companies from the list of Fortune 1000 companies. ${ }^{1}$ From this list, we selected companies that were (a) active Twitter users (companies that had a valid Twitter handle and had posted at least one tweet since 2019) in the timeline considered for this study, and (b) listed on the New York Stock Exchange (NYSE). This resulted in a set of 105 companies. For this exercise, we manually collected the Twitter handles of these companies from their corresponding websites.

We downloaded Twitter data for these companies using the tweepy API. This resulted in 189,303 tweets. We segmented the tweets by company and financial quarter. $T_{X, d}$ represents the set of tweets for company $X$ on day $d$.

$T_{X, d}=\{$ set of all tweets for company $X$ on day $d\}$

We used the text2emotions API to extract emotions in the tweets. ${ }^{2}$ The text2emotion library is designed by (Diaz et al. 2018). Since text2emotion is a new development, we performed manual cross-validation of the extracted emotions. Further, we used the

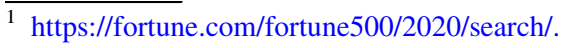

${ }^{2}$ https://pypi.org/project/text2emotion/\#description
} 
VADER (Valence Aware Dictionary and sEntiment Reasoner) lexicon, a sentiment analysis tool, to determine the sentiments expressed in tweets (Hutto and Gilbert 2014) and cross-validated the output of text2emotion with the output of VADER. The text2emotion with the output of VADER. The text2emotion API yielded a set of scores $\left\{s_{t, e}\right.$ foreache $\left.\in E\right\}$ where $E=\{$ set of basic emotions $\}=\{$ angry, fear, happy, sad, surprise $\}$. We derived the emotion score for each emotion in set $E$ using equation (1).

Score $\_$angry ${ }_{x, d}=$ Anger expressed in all tweets

$$
\begin{aligned}
& \text { for organization } X \text { on day } d \\
& \sum_{t \in T_{x, d} e=\text { anger }} S_{t, e}
\end{aligned}
$$

Similarly, we derive Score_Fear ${ }_{X, d}$, Score_Happy ${ }_{X, d}$, Score_Sad ${ }_{X, d}, \quad$ and Score_Surprise ${ }_{X, d}$. To eliminate the effect of variations in the quantum of emotion due to differences in tweet frequency, we used the emotion per tweet score for each emotion in set $E$. Emotion per tweet is calculated using Eq. (2).

$$
\begin{aligned}
& \text { Anger per tweet } \\
& =\text { Average of anger expressed in all tweets for } \mathrm{X} \text { on day d } \\
& =\frac{\sum_{t \in T_{X, d}, e=\text { anger }} s_{t, e}}{\left|T_{X, d}\right|} \text { where }\left|T_{X, d}\right| \text { represents cardinality of } T_{X, d}
\end{aligned}
$$

We downloaded the stock price data for companies from public sources. ${ }^{3}$ We used the closing stock price of companies for our analysis. We used the min-max scaled closing stock price (ScaledClose) as the dependent variable. HappyScore, AngryScore, FearScore, SadScore, SurpriseScore, and Crisis (dummy variable for crisis) acted as the independent variables. Extant literature have used several covariates to control the association between Twitter data and financial performance. Organization parameters such as firm age, firm size, and market conditions are known to influence the effect of Twitter data on financial performance (Yoon et al. 2018). Luo et al. (2013) have showed a significant association between tweet volume and stock price. Twitter usage metrics, such as Twitter age (measured as the number of days on Twitter), and the number of followers on the platform, indicate familiarity with Twitter use

\footnotetext{
3 https://finance.yahoo.com/.
}

(Rajadesingan et al. 2015). We use the size of the organization (measured in terms of the number of employees), tweet volume, and Twitter age as control variables.

As per published report, WHO became aware of the COVID-19 occurrence in China on December 31, 2019. ${ }^{4}$ The US reported the first confirmed COVID-19 case on January 21, 2020. Consequently, we considered the period between January 1, 2020, and June 30, 2020, as the crisis period (during the crisis or DC) for the analysis. The data extracted from January 1, 2019, to December, 31, 2019, was considered as before the crisis (BC). For regression analysis, the dummy variable crisis was assigned the value 1 to represent the crisis period and 0 to represent the non-crisis period. The cleaned and summarized data used for analysis contained 31,110 tweets. The DC time period consisted of 11,285 tweets and the BC time period consisted of 19,825 tweets.

\section{Analysis and Results}

Figure 1 presents the distribution of the number of tweets over time. A visual inspection of the plot indicates an increase in Twitter usage over the reported time period. The rate of increase appears sharper during the crisis period (DC). We compared the tweet frequency before the crisis and during the crisis using a t test. The $\mathrm{t}$ test (mean score $\mathrm{BC}=3.69$, mean score $\mathrm{DC}=5.57, p$ value $<0.001$ ) showed significantly higher frequency of organizational Twitter use DC compared to BC.

Comparing Twitter emotions

before and during crisis

Figure 2 plots the daily emotion score in tweets over the time period. A visual inspection of the plots showed an increase in sadness and fear emotions DC.

Table 1 provides a comparison of the emotion scores BC and DC. The analysis confirms a significant rise in all emotion scores DC compared to $\mathrm{BC}$. The increase in emotion scores for negative emotions (anger, fear, and sadness) DC matched the finding of the past studies that reported that crisis periods are

\footnotetext{
${ }^{4}$ https://www.who.int/news-room/detail/29-06-2020covidtimeline.
} 


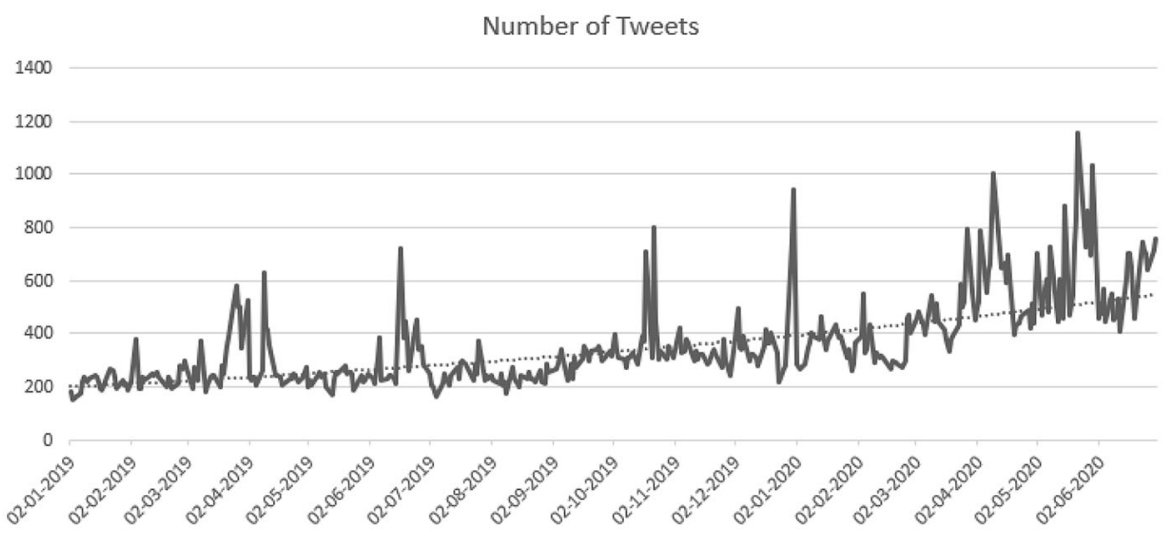

Fig. 1 Distribution of the number of tweets before and during crisis

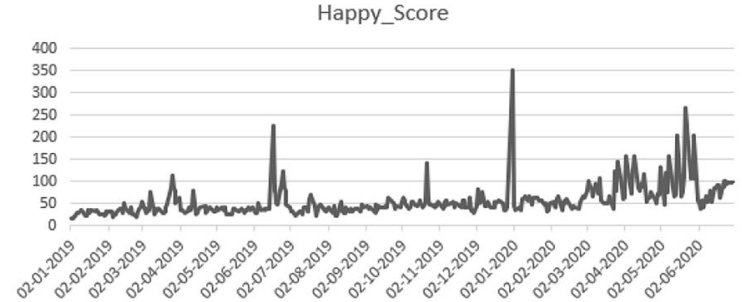

(a)

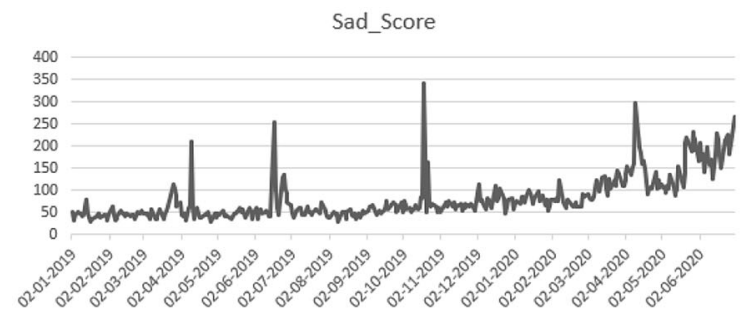

(c)

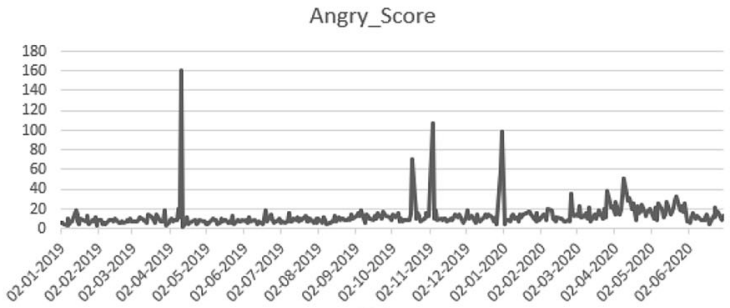

(b)

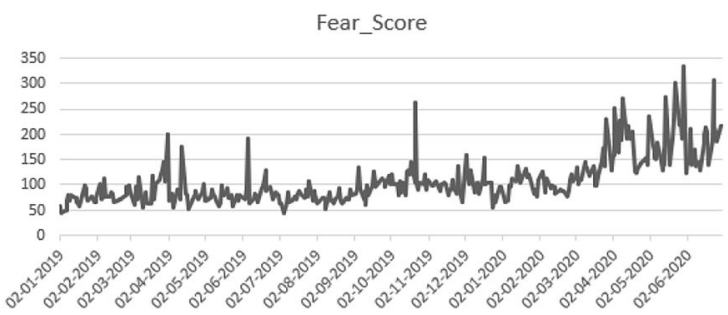

(d)

Fig. 2 Emotion scores of tweets for a happiness, $\mathbf{b}$ anger, $\mathbf{c}$ sadness, and $\mathbf{d}$ fear over time

characterized by an increase in negative emotion (Chew and Eysenbach 2010; Mandel et al. 2012).

We repeated the above analysis after replacing emotion score with emotion score per tweet. Figure 3 plots the emotion score per tweet over the time period. A visual inspection of the plots shows an increase in fear and sadness emotions during the crisis. Table 2 shows a comparison of the emotion score per tweet DC and $\mathrm{BC}$ for happiness, anger, fear, and sadness emotions. The results show a significant reduction in the happiness score per tweet, and a significant increase in the sadness score per tweet DC compared to BC. There was a significant decrease in anger score per tweet. There was no significant difference in fear per tweet between the two periods.

The analysis in this section showed an overall rise in the score for sadness emotion in organizational tweets during the COVID-19 crisis. The increase was shown at a gross level as well at a per tweet level. A visual inspection of Fig. $2 d$ appears to indicate an exponential rise in sadness DC. Though there was an overall rise in happiness score, the rise could be attributed to the rise in the number of tweets DC. A significantly lower happiness score per tweet DC 
Table 1 A comparison of emotion scores in organizational tweets before and during crisis

\begin{tabular}{llll}
\hline Emotion & Mean score BC & Mean score DC & $p$ value of t test \\
\hline Happiness & 0.563 & 0.837 & $<0.001$ \\
Anger & 0.137 & 0.168 & $<0.01$ \\
Fear & 1.113 & 1.634 & $<0.001$ \\
Sadness & 0.739 & 1.367 & $<0.001$ \\
\hline
\end{tabular}

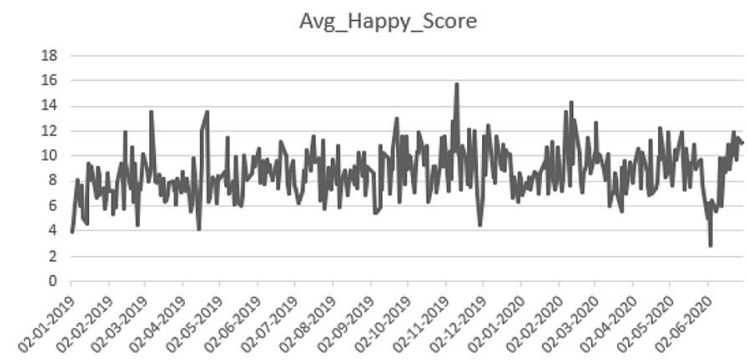

(a)

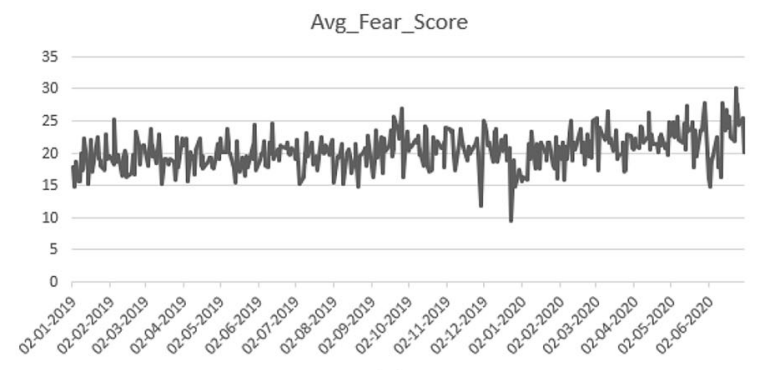

(c)

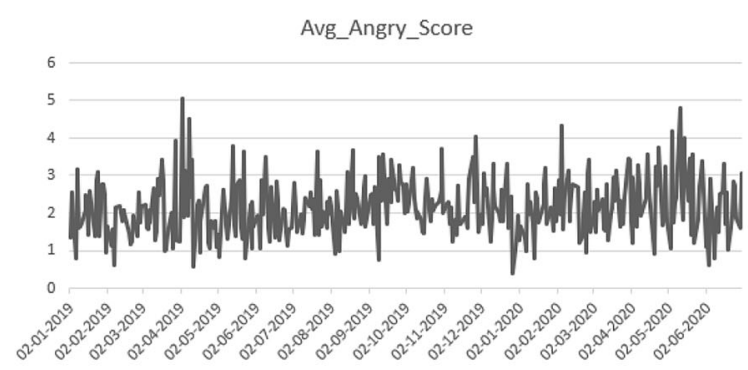

(b)

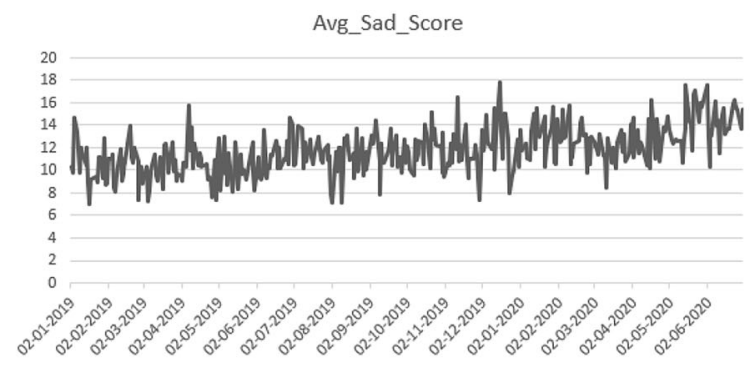

(d)

Fig. 3 Emotion score per tweets for a happiness, $\mathbf{b}$ anger, $\mathbf{c}$ fear, and $\mathbf{d}$ sadness over time

Table 2 A comparison of average emotion score per tweet before and during crisis

\begin{tabular}{llll}
\hline Emotion & Mean score BC & Mean score DC & $p$ value of t test \\
\hline Happiness & 0.108 & 0.099 & $<0.001$ \\
Anger & 0.266 & 0.249 & $<0.001$ \\
Fear & 0.252 & 0.239 & Not significant \\
Sadness & 0.141 & 0.145 & $<0.001$ \\
\hline
\end{tabular}

compared to BC indicated that the COVID-19 crisis had inflicted a reduction in happiness in organizational emotion. The analysis showed that the COVID-19 crisis did not result in increase in fear and anger emotions in organizational tweets.

Influence of volume of tweets on stock price

Figure 4 depicts the movement of the closing stock price of firms (ROCClose) over the considered time period. A visual inspection of the plot shows a higher fluctuation in the rate of change in stock prices DC compared to $\mathrm{BC}$.

Table 3 presents the results of the regression analysis performed to test the influence of the volume of tweets (TweetCount) on stock price of firms (ROCClose or ScaledClose). It is observed from Table 3 that Tweet volume is a significant positive predictor of ROCClose in the absence of any control variable. The predictor becomes not significant in the 


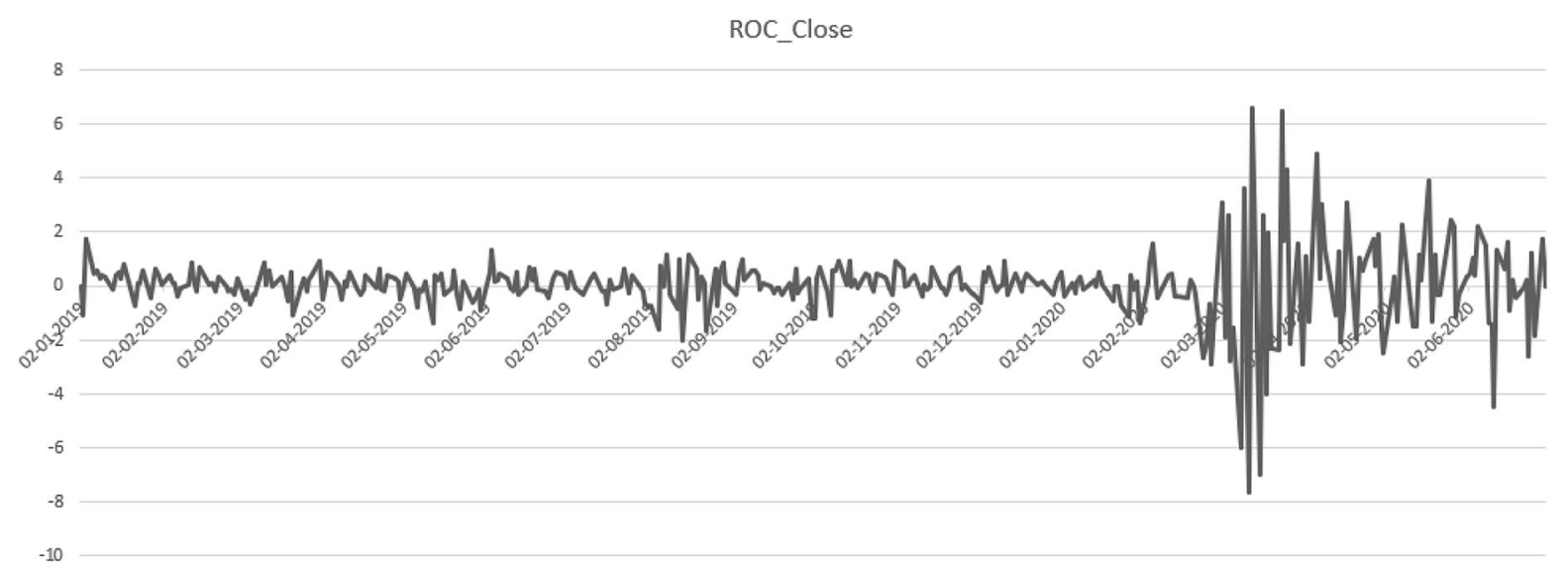

Fig. 4 Movement of stock prices of firms before and during the crisis

Table 3 Regression analysis showing the impact of tweet volume on stock price

\begin{tabular}{|c|c|c|c|c|c|c|c|c|}
\hline \multicolumn{9}{|c|}{ Dependent, independent, and control variables } \\
\hline DV & $\begin{array}{l}\text { ROC } \\
\text { close }\end{array}$ & ROC close & ROC close & ROC close & $\begin{array}{r}\text { Scaled } \\
\text { close }\end{array}$ & Scaled close & $\begin{array}{r}\text { Scaled } \\
\text { close }\end{array}$ & Scaled close \\
\hline $\mathrm{CV}$ & & $\begin{array}{l}\text { Size of org, } \\
\text { Follower } \\
\text { count, } \\
\text { Twitter age }\end{array}$ & Crisis & $\begin{array}{l}\text { Size of org, } \\
\text { Follower } \\
\text { count, } \\
\text { Twitter age, } \\
\text { Crisis }\end{array}$ & & $\begin{array}{l}\text { Size of org, } \\
\text { Follower } \\
\text { count, } \\
\text { Twitter age }\end{array}$ & Crisis & $\begin{array}{l}\text { Size of org, } \\
\text { Follower } \\
\text { count, } \\
\text { Twitter age, } \\
\text { Crisis }\end{array}$ \\
\hline IV & $\begin{array}{l}\text { Tweet } \\
\text { count }\end{array}$ & Tweet count & $\begin{array}{l}\text { Tweet } \\
\text { count }\end{array}$ & Tweet count & $\begin{array}{l}\text { Tweet } \\
\text { count }\end{array}$ & Tweet count & $\begin{array}{l}\text { Tweet } \\
\text { count }\end{array}$ & Tweet count \\
\hline \multicolumn{9}{|c|}{ Standardized coefficients $(\beta)$} \\
\hline $\begin{array}{l}\text { Tweet } \\
\text { count }\end{array}$ & $0.011 *$ & 0.011 & $0.013 *$ & $0.012 *$ & 0.007 & $0.012 *$ & $0.022 * * *$ & $0.024 * * *$ \\
\hline Size of org & & 0.000 & & 0.002 & & -0.005 & & $0.012 *$ \\
\hline $\begin{array}{c}\text { Followers } \\
\text { count }\end{array}$ & & 0.000 & & 0.000 & & $0.012 *$ & & $0.012 *$ \\
\hline Twitter age & & 0.003 & & 0.003 & & $-0.059 * * *$ & & $-0.057 * * *$ \\
\hline Crisis & & & $-0.024 * *$ & $-0.025^{* * *}$ & & & $-0.218 * * *$ & $-0.218 * * *$ \\
\hline \multicolumn{9}{|l|}{ Model fit } \\
\hline Significance & $<0.05$ & $\begin{array}{l}\text { Not } \\
\quad \text { significant }\end{array}$ & $<0.001$ & $<0.001$ & $\begin{array}{l}\text { Not } \\
\text { significant }\end{array}$ & $<0.001$ & $<0.001$ & $<0.001$ \\
\hline$R^{2}$ & 0.011 & 0.012 & 0.027 & 0.027 & 0.007 & 0.061 & 0.218 & 0.225 \\
\hline
\end{tabular}

$C V$ control variable, $I V$ independent variable, $D V$ dependent variable

${ }^{*} p$ value $<0.05, * * ; p$ value $<0.01, * * * ; p$ value $<0.001$

presence of organization and Twitter usage control variables. Overall, the tweet volume has a significant positive relationship with stock price performance. The crisis has a strong and significant negative influence on stock price. The introduction of crisis as a variable makes tweet volume a significant predictor of stock price performance for both ROCClose and ScaledClose, irrespective of the presence of the 
Table 4 Regression analysis showing the impact of emotion score on Scaled close

\begin{tabular}{lllll}
\hline Independent Variable & Unstandardized Coefficient & Std. Error & Standardized Coefficient $(\beta)$ & Significance \\
\hline (Constant) & .605 & .001 & & $<0.001$ \\
HappyScore & .001 & .001 & .022 & $<0.01$ \\
AngryScore & -.002 & .001 & -.009 & Not significant \\
FearScore & -.003 & .001 & -.040 & $<0.001$ \\
SadScore & .002 & .000 & .028 & $<0.001$ \\
SurpriseScore & .001 & .001 & .008 & Not significant
\end{tabular}

Model Summary

DV: ROC close

Model Significance: $<0.001$

$R^{2}: 0.033$

organization and Twitter control variables. The introduction of crisis as a variable also improves the variability explained by the model. Introduction of Twitter age, number of followers, and size of the organization as control variables over and above the variable crisis improves the performance of the regression model showing the impact of tweet volume of ScaledClose.

Influence of emotions in tweets on stock price

We analyzed the influence of emotions expressed in organizational tweets on stock price performance (ScaledClose). Table 4 presents a summary of the regression analysis. The analysis showed that happiness score had a significant and positive influence on stock price. Anger (not significant) and fear (significant) showed a negative influence on stock price. Sadness showed a significant positive influence on stock price. Further, we analyzed the moderation effect of crisis on the association between emotion score and stock price. Table 5 presents a comparison of the regression models to measure the moderation effect of crisis. Models 1.0 through 1.5 showed that happiness and sadness had a significant positive influence on stock price and fear had mostly significant negative influence on stock price in the presence of the crisis variable. Anger showed a negative influence on stock price performance, though the association was not significant (except in the presence of the interaction term HappyScoreXCrisis). The models were significant and explained $4.9 \%$ of the variability in the dependent variable. The $R^{2}$ value did not show any improvement with the introduction of the interaction terms.

In the next step, we introduced the organizational and Twitter metrics as control variables, namely, size of the organization, Twitter age, and the number of followers, in the moderation analysis. Table 6 presents a summary of the analysis for the happiness emotion. The influence of the happiness score on stock price was positive and significant in the presence of crisis as a moderating variable (model 2.0). The influence of happiness score on stock price was stronger in the presence of the organizational and Twitter-related control variables (model 2.1). With the introduction of the interaction term HappyScoreXCrisis (model 2.2), the influence of the happiness score on stock price became even stronger. The interaction term was significant, indicating a moderation effect of the crisis on the association between happiness score and stock price.

Tables 7, 8 show the impact of fear and sadness scores on stock price, respectively. The influence of fear on stock price is not significant and the interaction term with crisis is not significant either. This shows that the crisis does not have a moderation effect on the fear score in the presence of organizational and Twitter-related control variables. The influence of sadness on stock price performance was positive and significant in the presence of crisis (model 4.0). The influence of sadness on stock price was stronger in the presence of organizational and Twitter-related control variables (model 4.1). The $R^{2}$ value improved in 
Table 5 A comparison of models showing the effect of crisis on the association between emotion scores in tweets and stock price

\begin{tabular}{|c|c|c|c|c|c|c|}
\hline $\begin{array}{l}\text { Model } \\
\text { description }\end{array}$ & Model 1.1 & Model 1.1 & Model 1.2 & Model 1.3 & Model 1.4 & Model 1.5 \\
\hline DV & Scaled close & Scaled close & Scaled close & Scaled close & Scaled close & Scaled close \\
\hline $\mathrm{CV}$ & $\begin{array}{l}\text { Happy score } \\
\text { Angry score, } \\
\text { Fear score, } \\
\text { Sad score, } \\
\text { Surprise score }\end{array}$ & $\begin{array}{l}\text { Angry score, } \\
\text { Fear score, } \\
\text { Sad score, } \\
\text { Surprise score }\end{array}$ & $\begin{array}{l}\text { Happy score, } \\
\text { Fear score, Sad } \\
\text { score, Surprise } \\
\text { score }\end{array}$ & $\begin{array}{l}\text { Happy score } \\
\text { Angry score, } \\
\text { Sad score, } \\
\text { Surprise } \\
\text { score }\end{array}$ & $\begin{array}{l}\text { Happy score } \\
\text { Angry score, } \\
\text { Fear score, } \\
\text { Surprise } \\
\text { score }\end{array}$ & \\
\hline IV & Crisis & $\begin{array}{l}\text { Happy score, } \\
\text { Crisis }\end{array}$ & $\begin{array}{l}\text { Angry score, } \\
\text { Crisis }\end{array}$ & $\begin{array}{l}\text { Fear score, } \\
\text { Crisis }\end{array}$ & $\begin{array}{l}\text { Sad score, } \\
\text { Crisis }\end{array}$ & $\begin{array}{l}\text { Happy score } \\
\text { Angry score, Fear score, } \\
\text { Sad score, Surprise score, } \\
\text { Crisis }\end{array}$ \\
\hline $\begin{array}{l}\text { Interaction } \\
\text { term }\end{array}$ & & $\begin{array}{l}\text { Happy score X } \\
\text { Crisis }\end{array}$ & $\begin{array}{c}\text { Angry score } \\
\text { XCrisis }\end{array}$ & $\begin{array}{l}\text { Fear score } \\
\text { XCrisis }\end{array}$ & $\begin{array}{c}\text { Sad score } \\
\text { XCrisis }\end{array}$ & $\begin{array}{l}\text { Happy score XCrisis, } \\
\text { Angry score XCrisis, } \\
\text { Fear score XCrisis, Sad } \\
\text { score XCrisis }\end{array}$ \\
\hline \multicolumn{7}{|c|}{ Standardized coefficients $(\beta)$} \\
\hline Happy score & $0.022 * *$ & $0.027 * *$ & $0.023 * *$ & $0.023 * *$ & $0.023 * *$ & $0.029 * *$ \\
\hline Angry score & -0.012 & $-0.012 *$ & -0.010 & -0.012 & -0.011 & -0.010 \\
\hline $\begin{array}{l}\text { Surprise } \\
\text { score }\end{array}$ & 0.001 & 0.001 & 0.002 & 0.000 & 0.002 & 0.003 \\
\hline Sad score & $0.041 * * *$ & $0.04 * * *$ & $0.041 * * *$ & $0.041 * * *$ & $0.033 * * *$ & $0.025^{*}$ \\
\hline Fear score & $-0.028 * *$ & $-0.023^{*}$ & $-0.026 * *$ & $-0.023^{*}$ & $-0.032 * * *$ & -0.019 \\
\hline Crisis & $-0.219 * * *$ & $-0.217 * * *$ & $-0.217 * * *$ & $-0.217 * * *$ & $-0.221 * * *$ & $-0.218 * * *$ \\
\hline $\begin{array}{l}\text { Happy score } \\
\text { XCrisis }\end{array}$ & & -0.01 & & & & -0.006 \\
\hline $\begin{array}{l}\text { Angry score } \\
\text { XCrisis }\end{array}$ & & & -0.009 & & & -0.008 \\
\hline $\begin{array}{l}\text { Fear score } \\
\text { XCrisis }\end{array}$ & & & & -0.007 & & -0.015 \\
\hline $\begin{array}{c}\text { Sad score } \\
\text { XCrisis }\end{array}$ & & & & & 0.013 & $0.026^{*}$ \\
\hline \multicolumn{7}{|c|}{ Model summary } \\
\hline $\begin{array}{l}\text { Model } \\
\text { significance }\end{array}$ & $<0.001$ & $<0.001$ & $<0.001$ & $<0.001$ & $<0.001$ & $<0.001$ \\
\hline$R^{2}$ & 0.049 & 0.049 & 0.049 & 0.049 & 0.049 & 0.049 \\
\hline
\end{tabular}

$C V$ control variable, $I V$ independent variable, $D V$ dependent variable

${ }^{*} p$ value $<0.05, * * ; p$ value $<0.01, * * * ; p$ value $<0.001$

model 4.1. With the introduction of the interaction term SadScoreXCrisis (model 4.2), the influence of sadness score on stock price weakened. The interaction term was not significant, indicating no moderation effect of crisis.

Finally, we explore the moderation effect of all emotions together, in the presence of the organizational and Twitter-related control variables. Table 9 presents the analysis. We depict model 1.0 again in Table 9 to make the comparison easier. In model 5.1, we introduce the organizational and Twitter-related control variables. In model 5.2, we introduce the interaction terms to model 5.1. The introduction of the non-emotional (organizational and Twitter) control variables makes anger score a significant negative predictor of stock price. It strengthens the influence of 
Table 6 A comparison of models showing the moderating effect of crisis on the association between happiness score and stock price of firms

\begin{tabular}{llll}
\hline Model Description & Model 2.0 & Model 2.1 & Model 2.2 \\
\hline DV & Scaled close & Scaled close & Scaled close \\
CV & & Size of org, Follower count , Twitter age & Size of org, Follower count, Twitter age \\
IV & Happy score, Crisis & Happy score, Crisis & Happy score, crisis \\
Interaction term & & & Happy score Xcrisis \\
Standardized coefficients $(\beta)$ & $0.020^{* * *}$ & $0.021^{* * *}$ & \\
Happy score & $-0.218^{* * *}$ & $-0.217^{* * *}$ & $0.030^{* * *}$ \\
Crisis & NA & $0.013^{*}$ & $-0.215^{* * *}$ \\
Size of org & NA & $0.013^{*}$ & $0.014^{*}$ \\
Follower count & NA & $-0.056^{* * *}$ & $0.013^{*}$ \\
Twitter age & NA & & $-0.056^{* * *}$ \\
Happy score XCrisis & NA & $<0.001$ & $-0.014^{*}$ \\
Model summary & $<0.001$ & 0.051 & $<0.001$ \\
Model significance & 0.047 & $R^{2}$ &
\end{tabular}

$C V$ control variable, $I V$ independent variable, $D V$ dependent variable

$* p$ value $<0.05, * * ; p$ value $<0.01, * * * ; p$ value $<0.001$

Table 7 A comparison of models showing the effect of crisis on the association between fear score and stock price

\begin{tabular}{llll}
\hline Model description & Model 3.0 & Model 3.1 & Model 3.2 \\
\hline DV & Scaled close & Scaled close & Scaled close \\
CV & & Size of org, Follower count , Twitter age & Size of org, Follower count, Twitter age \\
IV & Fear score, Crisis & Fear score, Crisis & Fear score, Crisis \\
Interaction term & & & Fear score XCrisis \\
Standardized coefficients $(\beta)$ & 0.007 & 0.010 & \\
Fear score & $-0.217^{* * *}$ & $-0.217^{* * *}$ & 0.012 \\
Crisis & & $0.014^{*}$ & $-0.217^{* * *}$ \\
Size of org & & $0.013^{*}$ & $0.014^{*}$ \\
Follower count & $-0.056^{* * *}$ & $0.013^{*}$ \\
Twitter age & & & $-0.055^{* * *}$ \\
Fear score XCrisis & & & -0.002 \\
Model summary & & $<0.001$ & $<0.001$ \\
Model significance & $<0.001$ & 0.051 & 0.051 \\
$R^{2}$ & 0.048 & &
\end{tabular}

$C V$ control variable, $I V$ independent variable, $D V$ dependent variable

${ }^{*} p$ value $<0.05, * * ; p$ value $<0.01, * * * ; p$ value $<0.001$

sadness and weakens the influence of fear on the dependent variable. It improves the variability explained by the model $\left(R^{2}=0.052\right)$. The introduction of the interaction terms (model 5.2) makes anger and fear scores insignificant predictors of stock price. It strengthens the influence of the happiness score on 
Table 8 A comparison of models showing the effect of crisis on the association between sadness score and stock price

\begin{tabular}{|c|c|c|c|}
\hline Model description & Model 4.0 & Model 4.1 & Model 4.2 \\
\hline DV & Scaled close & Scaled close & Scaled close \\
\hline $\mathrm{CV}$ & & Size of org, Follower count, Twitter age & Size of org, Follower count, Twitter age \\
\hline IV & Sad score, Crisis & Sad score, Crisis & Sad score, Crisis \\
\hline Interaction term & & & Sad score XCrisis \\
\hline \multicolumn{4}{|c|}{ Standardized coefficients $(\beta)$} \\
\hline Sad score & $0.032 * * *$ & $0.036 * * *$ & $0.032 * * *$ \\
\hline Crisis & $-0.219 * * *$ & $-0.219 * * *$ & $-0.220 * * *$ \\
\hline Size of org & & $0.013 *$ & $0.013 *$ \\
\hline Follower count & & $0.013^{*}$ & $0.012 *$ \\
\hline Twitter age & & $-0.058 * * *$ & $-0.058 * * *$ \\
\hline Sad score XCrisis & & & 0.005 \\
\hline \multicolumn{4}{|l|}{ Model summary } \\
\hline Model significance & $<0.001$ & $<0.001$ & $<0.001$ \\
\hline$R^{2}$ & 0.219 & 0.227 & 0.227 \\
\hline
\end{tabular}

$C V$ control variable, $I V$ independent variable, $D V$ dependent variable

${ }^{*} p$ value $<0.05, * * ; p$ value $<0.01, * * * ; p$ value $<0.001$

stock price. The interaction term Sad Score XCrisis is significant in the model. The $R^{2}$ value of model 5.2 remains unchanged, compared to model 5.1.

\section{Discussion}

Our analysis showed a significant increase in the organizational use of Twitter during the COVID-19 crisis. The increase was accompanied by a significant overall increase in both positive (happiness) and negative (anger, fear, and sadness) emotions. Further analysis showed a significant lower positive emotion (happiness) per tweet and a significantly higher negative emotion (sadness) per tweet during the crisis. The negative emotion scores of anger and fear per tweet did not show a significant increase. The analysis showed a positive association between volume of tweets and stock price. The volume of tweets retained a significant positive association with stock price during crisis. This association remained significant when controlled on the size of the organization, Twitter age, and number of followers on Twitter.

The emotion scores (happiness, fear, and sadness) in organizational tweets showed a significant impact on stock price. While positive emotion (happiness) showed a positive influence, negative emotion (fear) showed a negative influence on stock price. Interestingly, the negative emotion sadness showed a positive influence on stock price in the presence of the crisis variable. Anger showed a negative influence on stock price, but the impact was not consistently significant. It became a significant predictor of stock price in the presence of control variables and in the presence of the interaction term HappyScoreXCrisis.

The crisis played a pivotal role in the association between emotion scores and stock price of firms. Organizations increased their Twitter usage significantly during the crisis. The analysis showed sadness to be the predominant emotion in organizational tweets during the crisis. Happiness, anger, fear, and sadness emotions showed a significant association with stock price. The emotions in organizational tweets explained $5.2 \%$ of variability in the presence of crisis and the organizational and Twitter-related control variables. The analysis supported the importance of Twitter as a digital medium of communication and the emotions expressed in organizational tweets in a crisis. 
Table 9 A comparison of models on the effect of crisis on the association between sadness score and stock price

\begin{tabular}{|c|c|c|c|}
\hline Model Description & Model 1.0 & Model 5.1 & Model 5.2 \\
\hline DV & Scaled close & Scaled close & Scaled close \\
\hline $\mathrm{CV}$ & & $\begin{array}{l}\text { Size of org, Follower count, } \\
\text { Twitter age }\end{array}$ & $\begin{array}{l}\text { Size of org, Follower count } \\
\text { Twitter age }\end{array}$ \\
\hline IV & $\begin{array}{l}\text { Happy score, Angry score, Fear } \\
\text { score, Sad score, Surprise score, } \\
\text { Crisis }\end{array}$ & $\begin{array}{l}\text { Happy score, Angry score, Fear } \\
\text { Score, sad score, Surprise score, } \\
\text { Crisis }\end{array}$ & $\begin{array}{l}\text { Happy score, Angry score, Fear } \\
\text { score, Sad score, Surprise score, } \\
\text { Crisis }\end{array}$ \\
\hline Interaction term & & & $\begin{array}{l}\text { Happy score Xcrisis, Angry score } \\
\text { XCrisis, Fear score XCrisis, }\end{array}$ \\
\hline \multicolumn{4}{|l|}{ Sad score XCrisis } \\
\hline \multicolumn{4}{|l|}{$\begin{array}{l}\text { Standardized } \\
\text { coefficients }(\beta)\end{array}$} \\
\hline Happy score & $0.022 * *$ & $0.022 * *$ & $0.029 * *$ \\
\hline Anger score & -0.012 & $-0.012^{*}$ & -0.011 \\
\hline Fear score & $-0.028 * *$ & $-0.025 * *$ & -0.014 \\
\hline Sad score & $0.041 * * *$ & $0.044 * * *$ & $0.027 * *$ \\
\hline Surprise score & 0.001 & 0.000 & 0.002 \\
\hline Crisis & $-0.219 * * *$ & $-0.219 * * *$ & $-0.217 * * *$ \\
\hline Size of org & & $0.013 *$ & $0.013^{*}$ \\
\hline Follower count & & $0.013 *$ & $0.013^{*}$ \\
\hline Twitter age & & $-0.057 * * *$ & $-0.058 * * *$ \\
\hline $\begin{array}{l}\text { Happy score } \\
\text { XCrisis }\end{array}$ & & & -0.008 \\
\hline $\begin{array}{l}\text { Angry score } \\
\text { XCrisis }\end{array}$ & & & -0.016 \\
\hline Fear score XCrisis & & & -0.009 \\
\hline Sad score XCrisis & & & $0.027^{*}$ \\
\hline \multicolumn{4}{|l|}{ Model summary } \\
\hline Model significance & $<0.001$ & $<0.001$ & $<0.001$ \\
\hline $\mathrm{R}^{2}$ & 0.049 & 0.052 & 0.052 \\
\hline
\end{tabular}

$C V$ control variable, $I V$ independent variable, $D V$ dependent variable

${ }^{*} p$ value $<0.05, * * ; p$ value $<0.01, * * * ; p$ value $<0.001$

\section{Conclusion}

A majority of studies on crisis management have focused on measures for detecting and preventing crises (Coombs 1999). This study contributed to crisis communication in managing the financial performance of the organization. The COVID-19 is an instance of a crisis of unprecedented degree, that bears a large degree of uncertainty and social and economic consequences. This study investigated organizational communication during the COVID-19 crisis and its impact on managing the consequences of the crisis on organizational performance in the financial market.
The study offers academic researchers an insight into emotional content of organizational Twitter posts. It contributes to the academic literature on emotion mining from organizational Twitter data. The detailed analysis of constituent positive (happiness) and negative (anger, fear, and sadness) emotions in organizational tweets and their association with stock price of firms is a major contribution to the academic literature on the topic. Further, the paper contributes to the literature on organizational crisis management. It reinforces the importance of the role of Twitter communication and the emotions expressed in 
organizational tweets in determining an organization's performance in the stock market in the context of a crisis.

Unlike crisis events, such as natural calamities (earthquakes, storms) and accidents (fire, shoot outs), where the crisis duration is short, the COVID-19 is an ongoing crisis for an elongated and uncertain period. Future researchers need to take the research forward to study the pattern of organizational communication and its emotional content through the stages of the crisis. This paper offers practitioners several insights on the use of Twitter for organizational communication with internal and external stakeholders at various stages of a crisis and its influence on organizational performance. The analysis shows that an increase in Twitter posts improves stock price performance of a firm. Second, it beckons a need to manage emotional cues in organizational Twitter communication. Third, it emphasizes the positive role of happiness and negative role of anger and fear on stock price during a crisis. It indicates a need for organizational cognizance about emotions in their communication, even when the organization does not have a responsibility for the crisis. These practical implications will help organizations to improve their Twitter communication strategy in general; and effectively leverage digital media of communication, such as Twitter, during a crisis in particular. Regulators may use the analysis in managing and controlling public emotion in a crisis. We believe that this paper will contribute to the body of research and knowledge on organizational communication, organizational use of social networking, text mining, and organizational crisis response.

\section{References}

Barkur G, Vibha GBK (2020) Sentiment analysis of nationwide lockdown due to COVID 19 outbreak: evidence from India. Asian J Psychiatry. https://doi.org/10.1016/j.ajp.2020. 102089

Barton MA, Sutcliffe KM, Vogus TJ, DeWitt T (2015) Performing under uncertainty: contextualized engagement in wildland firefighting. J Conting Crisis Manag 23(2):74-83

Boin A (2009) The new world of crises and crisis management: implications for policymaking and research. Rev Policy Res 26(4):367-377

Chew C, Eysenbach G (2010) Pandemics in the age of Twitter: Content analysis of tweets during the $2009 \mathrm{H} 1 \mathrm{~N} 1$ outbreak. PLoS ONE. https://doi.org/10.1371/journal.pone.0014118
Coombs WT (1999) Information and compassion in crisis responses: a test of their effects. J Public Relat Res 11(2):125-142

Coombs WT (2007) Protecting organization reputations during a crisis: the development and application of situational crisis communication theory. Corp Reput Rev 10:163-176

Culnan MJ, McHugh PJ, Zubillaga JI (2010) How large US companies can use Twitter and other social media to gain business value. MIS Q Exec 9(4):243-259

De Choudhury M, Counts S (2012) The nature of emotional expression in social media: measurement, inference and utility. In Proceedings of the Human Computer Interaction Consortium Workshop, Austin, TX, USA, 5-10 May, pp. $1-10$

Dhar S (2019) Role of social networking sites in creating social capital: implications for businesses. Ph.D. Thesis, Aligarh Muslim University, Aligarh, India, p. 147

Diaz SS, Shaik JMM, Santofimi JCG, Quintero MCG (2018) Intelligent execution of behaviors in a nao robot exposed to audiovisual stimulus. In IEEE 2nd Colombian Conference on Robotics and Automation (CCRA), IEEE, Barranquilla, Atlántico, Colombia, 1-3 November, pp. 1-6

Dinev T, McConnell AR, Smith HJ (2015) Research commentary-informing privacy research through information systems, psychology, and behavioral economics: thinking outside the "APCO" box. InfSyst Res 26(4):639-655

Do HJ, Lim C-G, Kim YJ, Choi H-J (2016) Analyzing emotions in Twitter during a crisis: a case study of the 2015 Middle East respiratory syndrome outbreak in Korea. In international conference on big data and smart computing, (BigComp), Hong Kong, 18-20 January, pp. 415-418, https://doi.org/https://doi.org/10.1109/BIGCOMP.2016. 7425960

Fama EF (1970) Efficient capital markets: a review of theory and empirical work. J Financ 25(2):383-417

Fenton-O'Creevy M, Soane E, Nicholson N, Willman P (2011) Thinking, feeling and deciding: the influence of emotions on the decision making and performance of traders. J Org Behav 32(8):1044-1061

Fleming JH, Coffman C, Harter JK (2005) Manage your human sigma. Harv Bus Rev 83(7):106-115

Fredrickson BL, Tugade MM, Waugh CE, Larkin GR (2003) What good are positive emotions in crises? A prospective study of resilience and emotions following the terrorist attacks on the United States on September 11th, 2001. J PersSocPsychol 84(2):365-376

Goleman D (1998) Working with Emotional Intelligence. Bantam, New York

Grove H, Patelli L, Victoravich LM, Xu PT (2011) Corporate governance and performance in the wake of the financial crisis: evidence from US commercial banks. Corp GovInt Rev 19(5):418-436

Hutto CJ, Gilbert EE (2014) VADER: a parsimonious rulebased model for sentiment analysis of social media text. In: Eighth international conference on weblogs and social media 2014 (ICWSM-14), Ann Arbor, Michigan, USA, 1-4, June

Jin Y, Pang A, Cameron GT (2007) Integrated crisis mapping: towards a public-based, emotion-driven conceptualization in crisis communication. SpheraPublica 7:81-95 
Jin Y, Pang A, Cameron GT (2010) The role of emotions in crisis responses Inaugural test of the integrated crisis mapping (ICM) model. Corp CommunInt J 15(4):428-452

Kato Y, Kato S, Akahori K (2007) Effects of emotional cues transmitted in e-mail communication on the emotions experienced by senders and receivers. Comput Hum Behav 23:1894-1905

Laporte T, Consolini P (1991) Working in practice but not in theory: Theoretical challenges of "high-reliability organizations." J Public Adm Res Theory 1(1):19-48

Lu Y, Huang Y-HC (2018) Getting emotional: an emotioncognition dual factor model of crisis communication. Public Relat Rev 44(1):98-107

Luo P, Chen K, Wu C (2018) Measuring social influence for firm-level financial performance. Electron Commer Res Appl 20:15-29

Luo X, Zhang J, Duan W (2013) Social media and firm equity value. InfSyst Res 24(1):146-163

Mackinnon L, Bacon L, Cortellessa G, Cesta A (2013) Using emotional intelligence in training crisis managers: the Pandora approach. Int $\mathbf{J}$ Distance EducTechnol 11(2):66-95

Mandel B, Culotta A, Boulahanis J, Stark D, Lewis D, Rodrigue J (2012) A demographic analysis of online sentiment during hurricane Irene. In: proceedings of the second workshop on language in social media, Montréal, Canada, 7 June, pp. 27-36

Mao Y, Wei W, Wang B, Liu B (2012) Correlating S\&P 500 stocks with Twitter data. In first acm international workshop on hot topics on interdisciplinary social networks research, Beijing, China, 12 August, pp. 69-72

McKinsey (2020) COVID-19: implications for business April 2020 | Executive Briefing. Available at https://www. mckinsey.com/business-functions/risk/our-insights/covid19-implications-for-business. Accessed 14 April 2020

Nakashima M, Ota S (2016) Association between corporate financial performance and corporate social responsibility in a crisis: focusing on the March 11 disaster. Asia-Pac Manag Account J 11(2):147-167

Ortony A, Turner TJ (1990) What's basic about basic emotions? Psychol Rev 97:315-331

Osatuyi B, Yoosefi B (2019) You are what you say: the influence of company tweets on its stock performance. In: proceedings of the 52nd hawaii international conference on system sciences, Grand Wailea, HI, USA, 8-11 January, pp. $1668-1676$

Pastor CKL (2020) Sentiment analysis on synchronous online delivery of instruction due to extreme community quarantine in the Philippines caused by COVID-19 pandemic. Asian J Multidiscip Stud 3(1):1-6

Plutchik R (1980) A general psychoevolutionary theory of emotion. In: Plutchik R, Kellerman H (eds) Emotion: Theory, Research, and Experience, vol 1. Theories of Emotion. Academic Press, New York, pp 3-31

Rajadesingan A, Zafarani R, Liu H (2015) Sarcasm detection on Twitter: A behavioral modeling approach. In: Proceedings of the Eighth ACM International Conference on Web Search and Data Mining, Shanghai, China, 31 January-6 February, pp. 97-106

Seo M-G, Barrett LF (2007) Being emotional during decision making — good or bad? Academy of Management Journal, An empirical investigation. https://doi.org/10.5465/amj. 2007.26279217

Signorini A, Segre AM, Polgreen PM (2011) The use of Twitter to track levels of disease activity and public concern in the U.S. during the influenza A H1N1 pandemic. PLoS ONE. https://doi.org/10.1371/journal.pone.0019467

Simpson AV, Clegg S, Cunha MP (2013) Expressing compassion in the face of crisis: organizational practices in the aftermath of the Brisbane floods of 2011. J Conting Crisis Manag 21(2):115-124

Sinclaire JK, Vogus CE (2011) Adoption of social networking sites: an exploratory adaptive structuration perspective for global organizations. InfTechnolManag 12:293-314

Wang Y, Yang Y (2020) Dialogic communication on social media: how organizations use Twitter to build dialogic relationships with their publics. Comput Hum Behav 104:1-36

WEFORUM (2020) Here's what lockdown looks like around the world. Available at https://www.weforum.org/agenda/ 2020/04/coronavirus-lockdowns-global/. Accessed 19 April 2020

WHO (2020) WHO Timeline-COVID-19. Available at https:// www.who.int/news-room/detail/08-04-2020-whotimeline-covid-19. Accessed 19 April 2020

Williams TA, Gruber DA, Sutcliffe KM, Shepherd DA, Zhao EY (2017) Organizational response to adversity: fusing crisis management and resilience research streams. AcadManag Ann 11(2):733-769

Wisittigars B, Siengthai S (2019) Crisis leadership competencies: the facility management sector in Thailand. Facilities 37(13/14):881-896

Yin D, Bond SD, Zhang H (2014) Anxious or angry? Effects of discrete emotions on the perceived helpfulness of online reviews. MIS Q 38(2):539-560

Yoon G, Li C, Ji Y, North M, Hong C, Liu J (2018) Attracting comments: digital engagement metrics on Facebook and financial performance. J Advert. https://doi.org/10.1080/ 00913367.2017 .1405753

Yu Y, Duan W, Cao Q (2013) The impact of social and conventional media on firm equity value: a sentiment analysis approach. Decis Support Syst 55(4):919-926

Zhou Z, Zhao J, Xu K (2016) Can online emotions predict the stock market in China? In: Conference on Web Information Systems Engineering, Shanghai, China, 8-10 November, pp. $328-342$

Publisher's Note Springer Nature remains neutral with regard to jurisdictional claims in published maps and institutional affiliations. 